\title{
Ignacio Arellano y Gonzalo Santonja Gómez-Agero (eds.), La hora de los asesinos: crónica negra del Siglo de Oro, New York, Instituto de Estudios Auriseculares (IDEA), 2018, 184 pp. ISBN: 978-1-938795-49-7
}

\section{Daniele Arciello}

Universidad de León

ESPAÑA

arciellod@gmail.com

[Hipogrifo, (issn: 2328-1308), 8.1, 2020, pp. 647-652]

Recibido: 30-01-2020 / Aceptado: 14-02-2020

DOI: http://dx.doi.org/10.13035/H.2020.08.01.43

El tema de este volumen versa sobre aquel conjunto de aspectos que son los más representativos del lado "oscuro" de la literatura aurisecular: con frecuencia, los asesinos protagonizaban los relatos y las piezas teatrales de mayor auge de la época y desde luego su pervivencia temática se percibe en la prosística actual. Así, no es casual que en su prefacio Gonzalo Santonja Gómez-Agero no dude en equiparar una novela del siglo XX, (Ojerosa y pintada (1960) del mexicano Yáñez Delgadillo) con los eventos criminosos relatados en muchas creaciones pertenecientes a la novelística o al mundo del tablado. Al presentar los capítulos que componen el ensayo, Gómez-Agero adopta un estilo narrativo que recuerda el propio contenido de las obras que han sido objeto de estudio por los especialistas que han aportado sus observaciones. Por ende, resulta ser una manera eficaz de abrir la lectura de este interesante grupo de trabajos críticos, fruto de la colaboración entre el Instituto Castellano y Leonés de la Lengua y el Grupo de Investigación Siglo de Oro de la Universidad de Navarra.

El primero de dichos trabajos es de Ignacio Arellano Ayuso, quien en «La hora de los asesinos. Crónica negra del Madrid barroco» presenta un discurso sobre la abundancia de noticias delictivas que Jerónimo de Barrionuevo recopiló en sus Avisos, compuestos estos con el objeto de informar al amigo, un clérigo de Zara- 
goza, acerca de todo lo relacionado con la vida cultural, económica y social en la capital. En particular, los acontecimientos narrados por el epistológrafo granadino insisten a menudo en la brutalidad con la que perpetraban los delitos más tremebundos, con detalles sangrientos o grotescos, en consonancia a veces con el gusto típicamente barroco de la época, como bien apunta Arellano Ayuso. El especialista ahonda en la infinidad de facetas que componen el mundo del crimen; los ejemplos más llamativos se exponen con un estilo que se armoniza con las emociones que tales actos suscitan en el lector de ayer y de hoy. Con ironía y cierto humor negro, Arellano Ayuso nos introduce en este (sub)mundo, acompañando a Barrionuevo en su recorrido de la violencia. Nos encontramos con un muestrario muy variado de casos en los que, tanto en la esfera familiar como en la pública, los madrileños asesinan indiscriminadamente a desconocidos o a sus propios familiares. Se confrontan, pues, dos ópticas de cronotopos diferentes, pero que tienen en común el interés por estas manifestaciones de la ferocidad humana.

De índole distinta es el breve repaso en torno al feminicidio que José María Díez Borque realiza en su «Homicidio femenino, teatro del Siglo de Oro y ley». Según el crítico, la escenificación de un asesinato materializaba el deseo del espectador por librarse de las ataduras de lo rutinario. Aquellas representaciones desempeñaban un papel preeminente en los debates que solían surgir cuando se ponía en tela de juicio la posible influencia emotiva que las funciones ejercían en el ánimo de los espectadores, impulsándolos a emular los delitos contenidos en dichas obras. Tras ello, Díez Borque pasa a realizar un análisis de un subgrupo de ejecuciones: el feminicidio. Al parecer, la legitimidad de dicho acto se fundamentaba en aquello que el código de honor dictaminada en función de los casos de incesto específicos y de la categoría social a la que pertenecieran los delincuentes. Todo ello se veía intensificado en los dramas, que no siempre encontraba su correspondiente en la realidad. Díez Borque subraya, asimismo, que el aparato jurídico en ocasiones ratificaba la justicia personal en relación con aquellas situaciones. En su conjunto, el autor proporciona un respaldo bibliográfico jurisdiccional de gran interés que ayuda a comprender las decisiones tomadas en materia de asesinatos de mujeres.

La lectura crítica de un drama lopiano corre a cargo de Juan Manuel Escudero Baztán en «Relato de un asesinato múltiple. Los comendadores de Córdoba de Lope de Vega» en el que amplía las consideraciones formuladas en un trabajo anterior, «Violencia y género en Los comendadores de Córdoba de Lope de Vega». Se trata de una reinterpretación de un hecho ocurrido en la Córdoba del siglo XV, cuya atrocidad despertó la curiosidad de muchos escritores. De hecho, la fuente que manejó Lope de Vega no es histórica, sino literaria: el Romance de los Comendadores (1596) de Rufo fue el texto que inspiró la teatralización de aquel acontecimiento que Escudero Baztán propone incorporar en la producción inicial del fénix de los ingenios. Esta propuesta de catalogación se justificaría por una inmadurez que se traduce en una carencia de homogeneidad estructural y en una construcción verbal poco impactante. Sobre todo, señala el crítico, la acumulación de eventos que conllevan el truculento desenlace, en el que mueren todos los actantes principales, adolece de desequilibrio narrativo, aspecto este que revalida la poca experiencia del dramaturgo en esa fase de su producción. Así pues las conclusiones a las que llega 
el autor del ensayo ponen énfasis en que Lope infunde en Los comendadores una comicidad cercana al humor negro y que hiperboliza una violencia que quizás no se corresponda con una fase posterior y más madura del dramaturgo madrileño.

De sabor sapiencial es, en cambio, La mujer que manda de Tirso de Molina. Naïma Lamari, con su aportación «Jezabel de La mujer que manda en casa de Tirso: retrato de un tirano», centra sus indagaciones en una figura que en la Sagrada Escritura se reputa de modelo antitético de la esposa virtuosa y sumisa, Raquel. El mercedario no duda en intensificar aquellos rasgos negativos para su trasposición teatral: la historia de Jezabel a la postre acaba convirtiéndose en material provechoso para sus fines didácticos. No es de extrañar, pues, que Tirso utilice técnicas y objetos escenográficos con el fin de perfilar una versión sensual, pérfida y caprichosa de la esposa de Acab. En suma, ella encarna los vicios más aborrecibles en una mujer; incluso los adornos lujosos y los momentos festivos invitan a una reflexión sobre la apariencia engañosa de las cosas y la frivolidad casi cómica de una comparación de Jezabel con los astros. A ello se añade la significación alegórica de la presencia de animales vinculados con la maldad y lo infernal (perros, caballos, halcones, etc.), dotando así a la "tirana" de un halo de perversidad sumamente relevante. Lamari hace hincapié en dicho arquetipo de vileza con una válida síntesis de los recursos que emplea el autor de la pieza, si bien la puntuación en el trabajo perjudica en ocasiones la fluidez de su estudio.

Con palabras introductorias de inspiración casi fabulística, Carlos Mata Induráin nos guía por los derroteros de una ficcionalización de una existencia, la del conde de Villamediana, cuyas vicisitudes resultaron más atractivas que sus propios escritos. En efecto, la conversión en dramas es el argumento central de «"La verdad del caso ha sido...": la muerte del conde de Villamediana en cuatro recreaciones dramáticas (1837-2008)». Lo ficcional, pues, suplanta a lo biográfico por medio de una revalorización de la vida del conde que, tras una época de olvido de tres siglos, comienza en el siglo XIX y se extiende hasta nuestros días. Mata Induráin no deja de recordarnos que la dramaturgia española manifestó un nuevo interés en las aventuras de Juan de Tasis y Peralta con cuatro recreaciones compuestas, respectivamente, en 1837, 1925, 1988 y 2008, de las cuales las dos últimas nunca se pusieron en escena. Dejando de lado los asuntos políticos que involucraron al noble, se asiste a una exaltación de su personalidad debida a la inclinación romántica que caracterizaba el teatro decimonónico y que pervive en el actual. A este respecto, Mata Induráin lleva a cabo un escrutinio que facilita con exhaustividad datos relativos no solo a las motivaciones que impulsaron la elección de dicho tema, sino también a los anacronismos, las discrepancias históricas o el énfasis dramático en uno u otro personaje que estructuran cada versión.

Con un íncipit tal vez excesivamente tendencioso, al utilizar términos como "fracasado" o "cínico" para referirse a la figura y al pensamiento del estadista Maquiavelo, Felipe B. Pedraza Jiménez y Milagros Rodríguez Cáceres, en su «Matar por razón de Estado. El asesinato político en Enríquez Gómez», delinean un parangón de sesgo político-moral entre el funcionario florentino y el autor de Cuenca, Antonio Enríquez Gómez. Este último, según los dos críticos, al patentizar la incompatibi- 
lidad de sus ideas con las del pensador italiano, proclamaba la superioridad de la religión frente al raciocinio humano; de hecho, publicó tratados cuyas propuestas rozaban con lo utópico cristiano. A la luz de ello, claramente sus piezas casaban con su mentalidad; en ellas, la separación entre bien y mal jamás se cuestionaba. Pedraza Jiménez y Rodríguez Cáceres postulan que héroes y villanos se revelaban tales desde el principio. Los asesinatos se revestían de un halo didáctico-alegórico que encajaba con los conocimientos bíblicos de quien los plasmaba y se ajustaban a los diferentes géneros del drama español. La reelaboración de anécdotas hagiográficas y eventos reales servía de medio para comunicar al público su postura política, a la vez que demostraba su aversión por Maquiavelo y su legitimación por el uso de la violencia, acorde a lo sostenido por ambos investigadores.

Un breve estudio sobre el ámbito bufonesco ítalo-español nos lo ofrece Victoriano Roncero López con su «Asesinos tragicómicos». Ilustra cómo las bromas que gastaban aquellos que entretenían a los cortesanos podían teñirse con la sangre de sus blancos o, al revés, repercutían negativamente en la salud de los propios juglares. Lo gracioso, pues, respondía a las pautas de una concepción de la diversión que se aleja de los paradigmas actuales, dado que aquella agresividad chistosa de ordinario terminaba hiriendo o matando a las víctimas quienes, a su vez, buscaban vengarse de manera cruenta a la primera ocasión favorable. Antológico fue el fallecimiento de don Francés de Zúñiga; Roncero López nos cuenta que el bufón, al perder sus protectores -Carlos I por echarlo de su corte y el duque de Béjar por haber fallecido-, no pudo defenderse del castigo letal de sus adversarios. En otra historia, el autor relata que el ferrarés Gonnella murió de susto cuando simularon su ejecución y, al percibir el agua fría que le arrojaron para fingir el espadazo que le decapitaría, su corazón se detuvo para siempre. Por el contrario, hay cuentos que hablan de graciosos que, al devolver una humillación anteriormente recibida, daban golpes tan furiosos que acababan con la vida del desgraciado. En cualquier caso, Roncero López nos recuerda que aquel discutible humorismo hallaba su justificación al reflejar una ansiada huida de la austeridad cristiana.

Sergio Santiago Romero tematiza el delito de honor en su «Carnaval de honor en el teatro breve de Calderón y su diálogo con Valle-Inclán», esbozando una comparativa entre el insigne madrileño y el ilustre gallego. Ya desde el principio esclarece los puntos medulares de su trabajo: a) don Ramón Valle-Inclán no conocía los entremeses calderonianos; b) pese a ello, las convergencias entre sendos dramaturgos son muchas; c) Santiago Romero coincide con algunos críticos en la continuidad temática de lo esperpéntico, que germinó en el corpus de Calderón y alcanzó su punto álgido con Valle-Inclán; d) este último denostaba el trabajo del literato barroco en lo que respecta al tratamiento del honor en sus dramas. Santiago Romero continúa su análisis afirmando que dicho menosprecio derivase de una perspectiva de raigambre ilustrada que condenaba a Calderón por apoyar implícitamente al régimen absolutista en sus escritos. De ahí que se creyera que sus obras respaldaban los asesinatos, bien entendido que se cometieran por el bien del Estado. No obstante, en sintonía con lo asentado por Santiago Romero, queda claro que son reflexiones anacrónicas y se han de tomar en cuenta solo aquellas que acomunan lo esperpéntico de Valle-Inclán con lo grotesco calderoniano, especialmente por 
la intención compartida de reflejar la realidad - con mayor fidelidad- mediante la deformación caricatural.

Santonja Gómez-Agero elige un registro menos formal y más expresivo a la hora de referir la falta de compasión de cinco capataces. Los abusos que perpetraron en daño de los forzados, en una mina de azogue, señala el especialista, se recopilaron en los informes del entonces contador Mateo Alemán. El funcionario interrogó a muchos reclusos, los cuales habían de aguantar tanto el inexorable envenenamiento por el mercurio como las tropelías de sus veedores. Gómez-Agero recalca la conducta despiadada de Miguel Brete, quien utilizaba brutalmente su bastón para vejar a los presos, lo que explica el sugerente título de este capítulo, «Le daba con el palo». El testimonio más fiable, el de un fraile agustino, permitió que el inspector consiguiera un cuadro más realista en torno a las iniquidades que tenían lugar en Almadén, puesto que Brete y sus compañeros tuvieron que acatar a las órdenes de los Fúcares, banqueros alemanes que gestionaban todo el negocio. El autor nos explica cómo una mejora que, inicialmente benefició a los trabajadores se suprimió porque los Fúcares decretaron posteriormente una explotación intensiva del yacimiento, lo cual originó un regreso a las injusticias iniciales. Muy pertinentes son las conclusiones de Gómez-Agero de cara a la futilidad del documento de Guzmán y a la controvertida hipótesis de una interpolación de su experiencia en su obra más famosa, El Guzmán de Alfarache.

Otra tipología de información, la que encierran las relaciones de sucesos, constituye el núcleo de la contribución de Jesús M. Usunáriz: «Ejecutar al asesino: la justicia en el Siglo de Oro a través de las relaciones de sucesos». Cerca de veinte casos se desgranan en las páginas finales de este monográfico, y las conexiones entre la faceta efectista de aquellas narraciones y la actualidad periodística de nuestra época dan aún más sentido a la decisión de cerrar así el volumen. También se observa la atingencia con el estudio previamente reseñado de Arellano y, al igual que aquel, en este distinguimos una gran variedad de crímenes sanguinarios: uxoricidios, canibalismo, infanticidios, homicidios por codicia o pasiones amorosas; ni siquiera las mujeres embarazadas no se escapan de su destino cruel. La diferencia reside en que en este caso las noticias se dan vía composiciones poéticas -coplas, jácaras, romances-, lo cual enfatiza la seducción de la sangre que cautivaba al público. En el epílogo, Usunáriz inserta con acierto las ejecuciones por cada caso criminoso anteriormente citado; sus descripciones muestran una tipificación de sentencias tachonadas de penas durísimas y aleccionadoras. Al fin y al cabo, todo había de concurrir en la ejemplaridad de una penitencia pública que inducía a la confianza en la expiación final y en las leyes, tanto humanas como divinas.

Para concluir esta breve recensión, podemos constatar que se precisa la elaboración de un considerable número de anotaciones críticas para abordar cabalmente una cuestión muy compleja y que establece un puente cronotópico entre pasado y presente, como es la interpretación literaria de la muerte violenta a manos de alguien. De ello se colige que, tanto en los escenarios como en poemas, relatos o demás creaciones de difícil compartimentación genérica, hay matices de estilo y contenido que requieren una profundización por parte de aquellos versados en 
asuntos filológicos. Por tanto, se han de valorar las apreciaciones de quienes han penetrado en las modalidades de amoldamiento ficcional delictivo que realizaron los autores auriseculares, discerniendo con acuidad la variedad de crímenes que se examinan en los iluminadores capítulos de La hora de los asesinos. 